Article

\title{
Optoelectronic and Electrothermal Properties of Transparent Conductive Silver Nanowires Films
}

\author{
Yuehui Wang $1, * \mathbb{D}$, Dexi Du ${ }^{1,2}$, Xing Yang ${ }^{1,2}$, Xianfeng Zhang ${ }^{1, *}$ and Yuzhen Zhao ${ }^{3}$ \\ 1 Zhongshan Institute, University of Electronic Science and Technology of China, Zhongshan 528402, China; \\ dudexi_work@foxmail.com (D.D.); shirleywyh@126.com (X.Y.) \\ 2 School of Materials and Energy, University of Electronic Science and Technology of China, \\ Chengdu 610054, China \\ 3 Department of Materials Science and Engineering, Tsinghua University, Beijing 100084, China; \\ zhaoyz@mail.tsinghua.edu.cn \\ * Correspondence: wangzsedu@126.com (Y.W.); zhangxf07@gmail.com (X.Z.); \\ Tel.: +86-760-8832-5402 (Y.W. \& X.Z.)
}

Received: 6 May 2019; Accepted: 10 June 2019; Published: 21 June 2019

\begin{abstract}
Silver nanowires (AgNWs) show promise for fabricating flexible transparent conductors owing to their excellent conductivity, high transparency, and good mechanical properties. Here, we present the fabrication of transparent films composed of AgNWs with diameters of 20-30 nm and lengths of $25-30 \mu \mathrm{m}$ on polyethylene terephthalate substrates and glass slides substrates using the Meyer rod method. We systematically investigated the films' optoelectronic and electrothermal properties. The morphology remained intact when heated at $25-150{ }^{\circ} \mathrm{C}$ and the AgNWs film showed high conductivity (17.6-14.3 $\Omega \cdot \mathrm{sq}^{-1}$ ), excellent transmittance (93.9-91.8\%) and low surface roughness values (11.2-14.7 nm). When used as a heater, the transparent AgNW conductive film showed rapid heating at low input voltages owing to a uniform heat distribution across the whole substrate surface. Additionally, the conductivity of the film decreased with increasing bending cycle numbers; however, the film still exhibited a good conductivity and heating performances after repeated bending.
\end{abstract}

Keywords: silver nanowire; optoelectronic properties; electrothermal properties; transparent conductive film

\section{Introduction}

Transparent conductive films (TCFs) are one of the important parts of many optoelectronic devices such as touch panels, film heaters, and organic light-emitting diodes [1-5]. It is anticipated that TCFs will be applied as transparent film heaters (TFHs) in various applications, such as outdoor displays, vehicle window defrosters, or heat retaining windows [4-10]. Currently, indium tin oxide (ITO) is the most widely used TCF because of its outstanding optoelectronic properties compared with other materials [1-4]. However, its brittle ceramic properties and expensive vacuum deposition process limit its application in flexible TCFs. Meanwhile, ITO shows a slow temperature response owing to its intrinsic properties [2].

To replace ITO, several emerging materials have been developed, such as metal nanowires and meshes [6-9], graphene [3,4], Ga-doped $\mathrm{ZnO}$ [10], and carbon nanotubes [5]. However, some problems still need to be solved before those materials can be widely used for TFH application. Carbon nanotubes have large resistance and graphene's fabrication process is highly complex [11].

In recent years, silver nanowires (AgNWs) have been developed and now rank among the most promising candidate for replacing ITO owing to their excellent optoelectronic properties and large-scale and cost-effective fabrication process [12-16]. However, it has been a challenge to achieve both excellent 
optical transmittance and high conductivity because these two properties follow opposing trends, and this often results in optoelectronic performances far inferior to those of ITO [17-20]. Additionally, it is hard to obtain uniformly interconnected large-area AgNWs networks, particularly when using solution processes. Randomly non-uniform AgNWs networks result in the discontinuous heating of TFH. The literature indicates that the underlying reasons for the limited performance of AgNW films may be related to the morphology of the AgNWs and the processes used to obtain high quality AgNW film [21-26]. However, experimental and theoretical studies have shown that AgNWs with high aspect ratios are better for forming the uniform conductive networks that improve the optoelectronic properties of AgNW film [27-31], which is related to the various models for electrical percolation [32,33].

To the best of our knowledge, there are few reports that systemically investigate the effects of temperature on the optoelectronic and electrothermal properties transparent conductive AgNW films. The reason for this may be because AgNW films are mainly used at low temperatures, especially when used as flexible TCFs. In this study, we fabricated transparent films composed of AgNWs with diameters of 20-30 $\mathrm{nm}$ and lengths of 25-30 $\mu \mathrm{m}$ on polyethylene terephthalate (PET) and glass slides substrates using the Meyer rod method and systematically investigated the optoelectronic and electrothermal properties of AgNW films.

\section{Experimental Approach}

A $10 \mathrm{wt} \%$ solution of AgNWs (20-30 nm in diameter and 25-30 $\mu \mathrm{m}$ in length from Suzhou Gushi New Materials Co., Ltd., Suzhou, China) in isopropyl alcohol was diluted to $3.3 \mathrm{mg} \cdot \mathrm{L}^{-1}$. Then, the AgNWs solution was agitated in an ultrasonic bath for $5 \mathrm{~min}$. Further, $1 \mathrm{~mL}$ AgNWs solution was placed onto a PET substrate (from Hefei Microcrystalline Materials Co., Ltd., Hefei, China) with dimensions of $210 \mathrm{~mm} \times 297 \mathrm{~mm}$ or onto a glass slide substrate (from Jiangsu Shitai Experimental Equipment Co., Ltd., Shitai, China) with dimensions of $25 \mathrm{~mm} \times 75 \mathrm{~mm}$. Finally, a thin film was formed via the Meyer rod coating technique at a speed of $0.05 \mathrm{~mm} / \mathrm{s}$. Our coating process was performed at $26^{\circ} \mathrm{C}$ and at a relative humidity of $50-60 \%$. The wet films were air dried at room temperature for $2 \mathrm{~min}$ and then treated on digital hotplate at temperature between 25 and $250{ }^{\circ} \mathrm{C}$ for $20 \mathrm{~min}$. After the films had cooled down to room temperature, we measured their optoelectronic properties and analyzed the films' microstructures.

AgNWs-based film heater was made by attaching the two ends of the film to two electrodes (clips coated with copper foil). A direct current voltage was supplied by a power supply (GPD-3303s, Suzhou Guwei electronics Co., Ltd., Suzhou, China) to the film heater through those two clips coated with copper foil that contacted the film edges. An infrared thermal imager (UTi160G, Youlide Technology (China) Co., Ltd., Shenzhen, China) was used to measure the temperature of the film. Figure 1 shows a schematic of the process for preparing TCF of AgNWs (Figure 1a) and AgNWs film heater (Figure 1b).
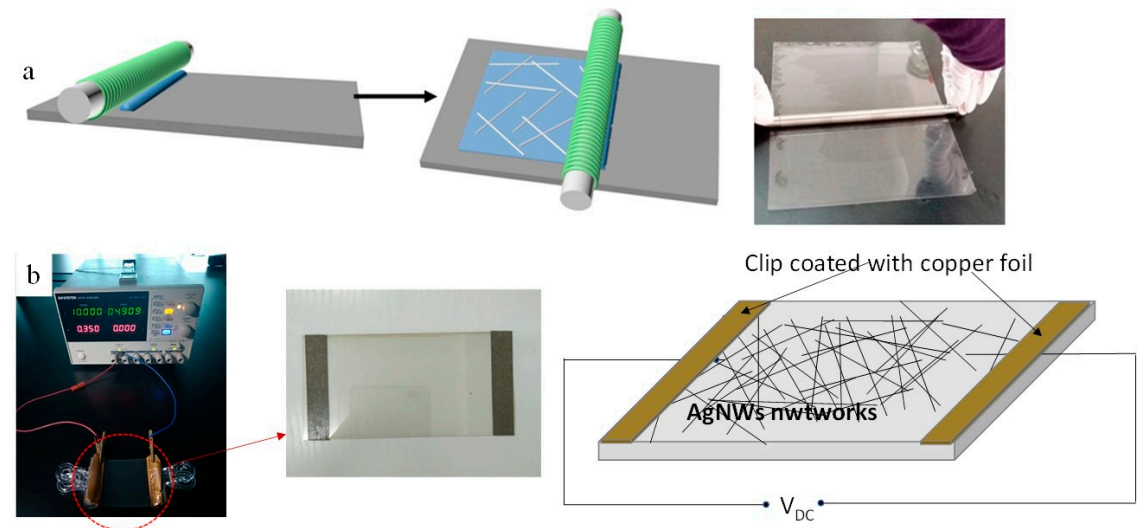

Figure 1. Schematic of the process for preparing: the transparent AgNW film; (a) and the AgNWs film heater (b). 
Differential scanning calorimetry (DSC) and thermogravimetric (TG) analysis were conducted via simultaneous differential thermal analysis (STA449F5, NETZSCH-Gertebau GmbH, Selb, Germany). The microstructures of AgNWs films were observed using scanning electron microscope (SEM, Zeiss sigma 500, Carl Zeiss, Jena, Germany), atomic force microscopy (Dimension Edge, Bruker, Billerica, MA, USA), and an optical microscope (Nikon LV100, Nikon Co., Ltd., Tokyo, Japan) with a digital camera. The sheet resistances of films were characterized using a four-point-probe system (ST2253, Suzhou Jingge Electronic Co., Ltd., Suzhou, China) and the optical transmittances were collected by a thin film transmittance meter (GZ502A, Shanghai Guangzhao Photoelectric Technology Co., Ltd., Shanghai, China). The optical transmittance and sheet resistance of each sample were each measured at twenty different sites and calculated from the average value of those measurements. The transmission and diffuse reflectance were measured with PET film as the reference. The surface morphology was analyzed via atomic force microscopy (Dimension Edge, Bruker, Billerica, MA, USA) and six different areas of the surface of sample were selected to obtain root mean square roughness (RMS) value and calculated as average value.

\section{Results and Discussion}

\subsection{Characterization of Silver Nanowires}

To further characterize the AgNWs, we observed the AgNW films via SEM (Figure 2a) and tested their thermal properties (Figure $2 b$ ). The inset image in Figure 2a shows a magnified view of the surface. Silver nanowires with diameters of 20-30 nm and lengths of 25-30 $\mu \mathrm{m}$ and nanoparticles can be observed in Figure 2a. As shown in Figure 2b, the DSC curve has three distinct endothermic peaks and one exothermic peak. In combination with the TG analysis curve, the rate of weight loss of the sample in the temperature of the first endothermic peak was as high as $91.50 \%$, which was caused by the volatilization of the isopropanol in the silver nanowire solution. The temperature of the second endothermic peak was about $189.52{ }^{\circ} \mathrm{C}$ and the rate of weight loss of the sample was about $92.10 \%$, which was caused by the surfactant decomposing and melting of the silver nanoparticles. Meanwhile, the third endothermic peak was at a temperature of about $332{ }^{\circ} \mathrm{C}$ and was caused by the melting of the silver nanostructures. The melting point of the AgNWs was about $197.35^{\circ} \mathrm{C}$, which is far below the melting point of bulk silver $\left(961.78^{\circ} \mathrm{C}\right)$.
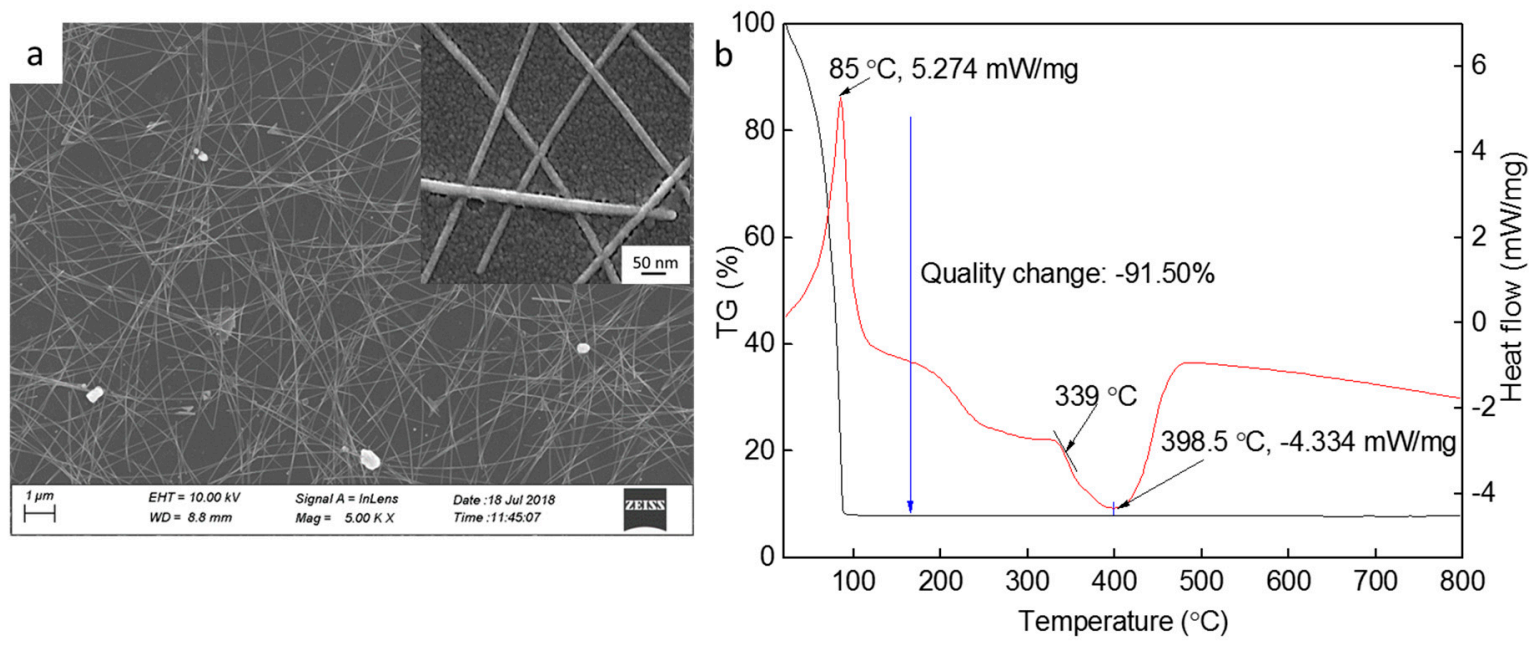

Figure 2. SEM image (a); and DSC and TG curves (b) of the AgNWs. The inset is the local magnification.

\subsection{Characterization of the Silver Nanowires Films}

Figure 3 shows SEM images of AgNWs films on glass slide substrates treated at 25, 100, 150, 170,200 , and $250{ }^{\circ} \mathrm{C}$ for $20 \mathrm{~min}$. AgNWs were coated to form random networks by overlapping one another on the substrate surface (Figure $3,25^{\circ} \mathrm{C}$ ). After heat-treating the sample at $100{ }^{\circ} \mathrm{C}$ for $20 \mathrm{~min}$, 
the morphology of the AgNWs did not show any obvious change. When the sample was heated at $150{ }^{\circ} \mathrm{C}$, it was found that the size of nanoparticles attached to the AgNWs became slightly larger. Increasing the heat treatment temperature further to $170^{\circ} \mathrm{C}$ caused the size of the nanoparticles to increase obviously larger and several notches formed in the AgNWs. Increasing the heat treatment temperature to $200{ }^{\circ} \mathrm{C}$ caused the AgNWs to sinter, breaking them into discontinuous segments; this indicates that the temperature of the heat treatment was above the melting point of AgNWs, which accelerated the diffusion of silver atoms at the nanowire surface. We then further increased the temperature of the heat treatment to $250{ }^{\circ} \mathrm{C}$, which caused the AgNWs to fuse into large droplets. Previous reports have also pointed out that high temperature heat treatment induced defects in AgNWs caused by vaporizations, resulting in the emergence of droplets from the AgNWs [31-33]. Here, the temperature at which the AgNWs fused into droplets was far lower than the temperatures reported in the literature [34,35]. The same phenomena were also confirmed by optical microscopy (see the Supplementary Materials, Figure S1). The sintering behaviors of nanomaterial are known to be similar to those of the bulk material, including Ostwald ripening, migration, and diffusion of atoms, which can then coalesce elsewhere [35-40]. The driving force for surface diffusion is the effective curvature of the free surface of the contact, and the larger is the curvature, the larger is the surface diffusion [40]. The driving force for surface diffusion changes with interface type following: nanoparticle-nanoparticle $>$ nanoparticle-nanowire $>$ nanowire-nanowire [36]. The driving force for neck growth between nanoparticles and interfaces with nanowire is higher than that between nanowire-nanowire interfaces [36]. This is also because atoms are tightly bonded along the nanowire, while the same does not occur at the nanoparticle level as they are "truncated" wires. We observed that the contact interfaces between the nanoparticles and the nanowires melted readily.
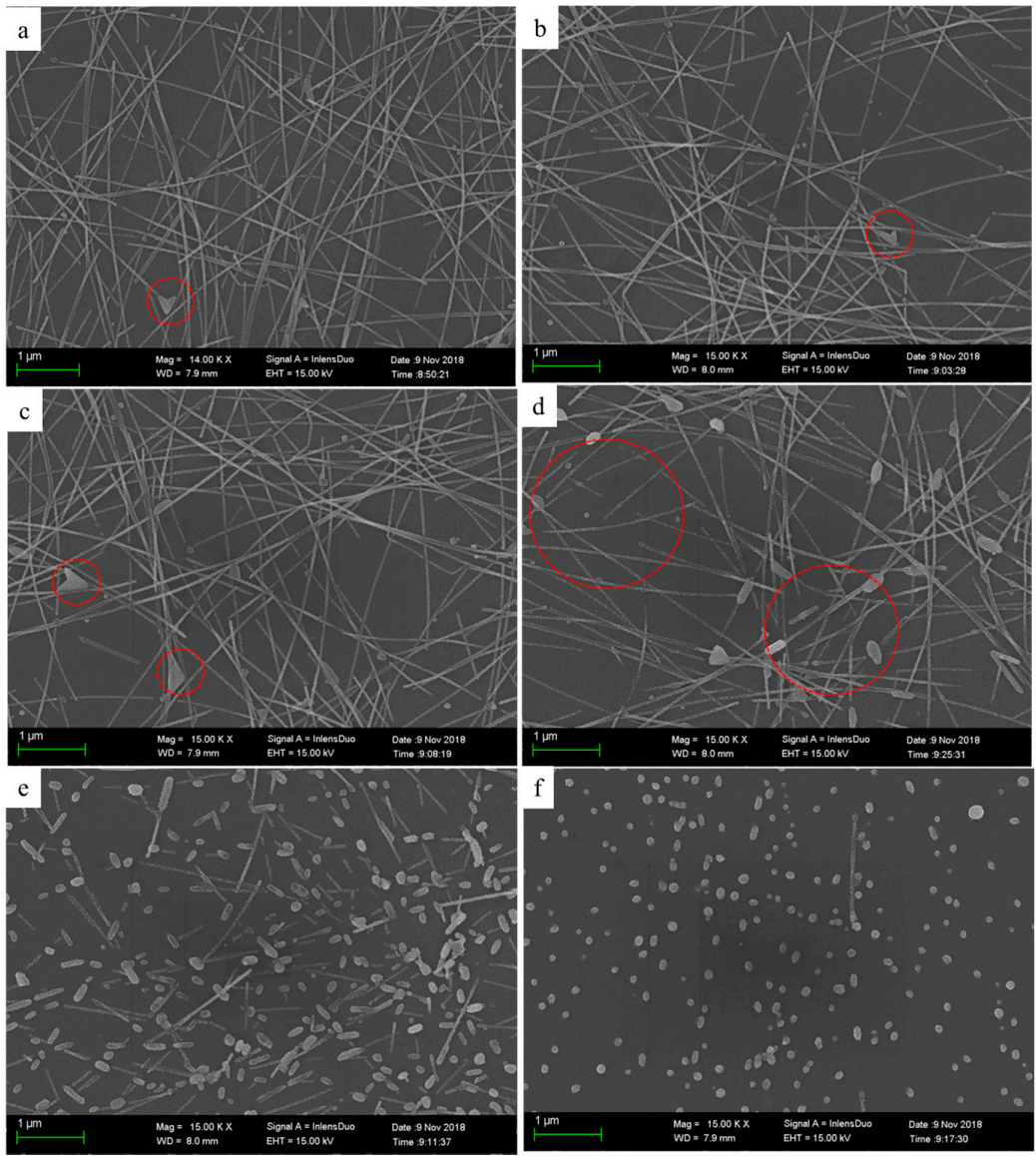

Figure 3. SEM images of AgNWs films treated at different temperatures, (a) 25, (b) 100, (c) 150, (d) 170, (e) 200 , and (f) $250{ }^{\circ} \mathrm{C}$ for $20 \mathrm{~min}$. 
The surface topography of the AgNWs films treated at 25, 100, 150, 170, 200, and $250{ }^{\circ} \mathrm{C}$ for $20 \mathrm{~min}$ were characterized using AFM operated in tapping mode, and the results are shown in Figure 4 (for three-dimensional (3D) images, see Supplementary Materials, Figure S2). The measured root mean square (RMS) roughness values for the corresponding samples were 11.2, 13.4, 14.7, 17.5, 17.9, and $19.1 \mathrm{~nm}$, respectively; these values are all smaller than the diameter of the AgNW. However, it is clear that the RMS film roughness increased along with the temperature of heat treatment. As shown in Figures 3 and 4, possible reasons for this are that the heat-treated nanoparticles and nanowires increased in size or that they formed discontinuous segments or droplets that protruded from the surface.
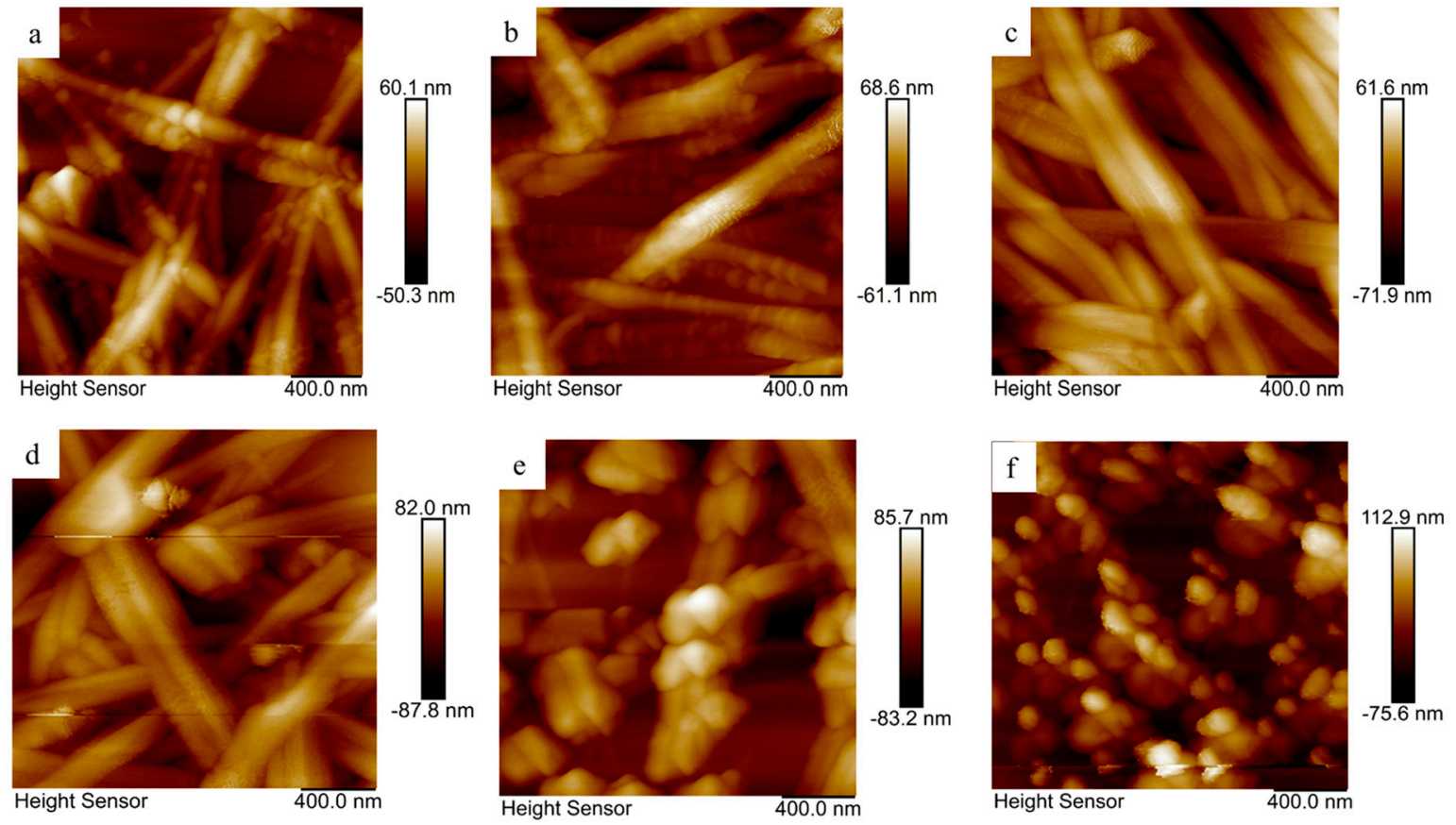

Figure 4. Surface topography of the AgNWs films treated at different temperatures, (a) 25, (b) 100, (c) 150, (d) 170, (e) 200 , and (f) $250{ }^{\circ} \mathrm{C}$ for $20 \mathrm{~min}$.

\subsection{Optoelectronic Properties of Silver Nanowires Films}

To understand the effects of temperature on the optoelectronic properties of the AgNWs films, we measured the transmittance values (Figure 5a) and sheet resistances (Figure 5b) of films treated at different temperatures for $20 \mathrm{~min}$. Curve a-f in Figure 5a represent the results for films treated at 25, $100,150,160,170$, and $180^{\circ} \mathrm{C}$, respectively. The inset in Figure 5a shows the relationship between the transmittance of the film at $550 \mathrm{~nm}$ and the heat treatment temperature. The transmittance and the sheet resistance of the films heated at $200{ }^{\circ} \mathrm{C}$ are not shown in Figure 5 because the sheet resistance of the film could not be determined, indicating that the film was not conductive. In Figure 5, it can be seen that the transmittance of the films gradually decreased as the temperature of the heat treatment increased. After heating at $25,100,150,160,170$, and $180{ }^{\circ} \mathrm{C}$, the transmittance values at $500 \mathrm{~nm}$ were $93.9 \%$, $93.1 \%, 91.8 \%, 91.3 \%, 90.7 \%$, and $87.0 \%$, respectively, and the sheet resistances of the corresponding films were $17.6,16.5,14.3,19.7,30.1$ and $108.1 \Omega \cdot \mathrm{sq}^{-1}$, respectively. Based on the experimental results presented in Figures 2-4, we can conclude that the AgNWs heated at $25-150{ }^{\circ} \mathrm{C}$ remained intact, and that those AgNW films had high conductivities (17.6-14.3 $\Omega \cdot \mathrm{sq}^{-1}$ ), excellent transmittance values (93.9-91.8\%) and low surface roughness values $(11.2-14.7 \mathrm{~nm})$; the films therefore have properties that are well-suited for applications in transparent heaters, touch-screen panels, and displays. 

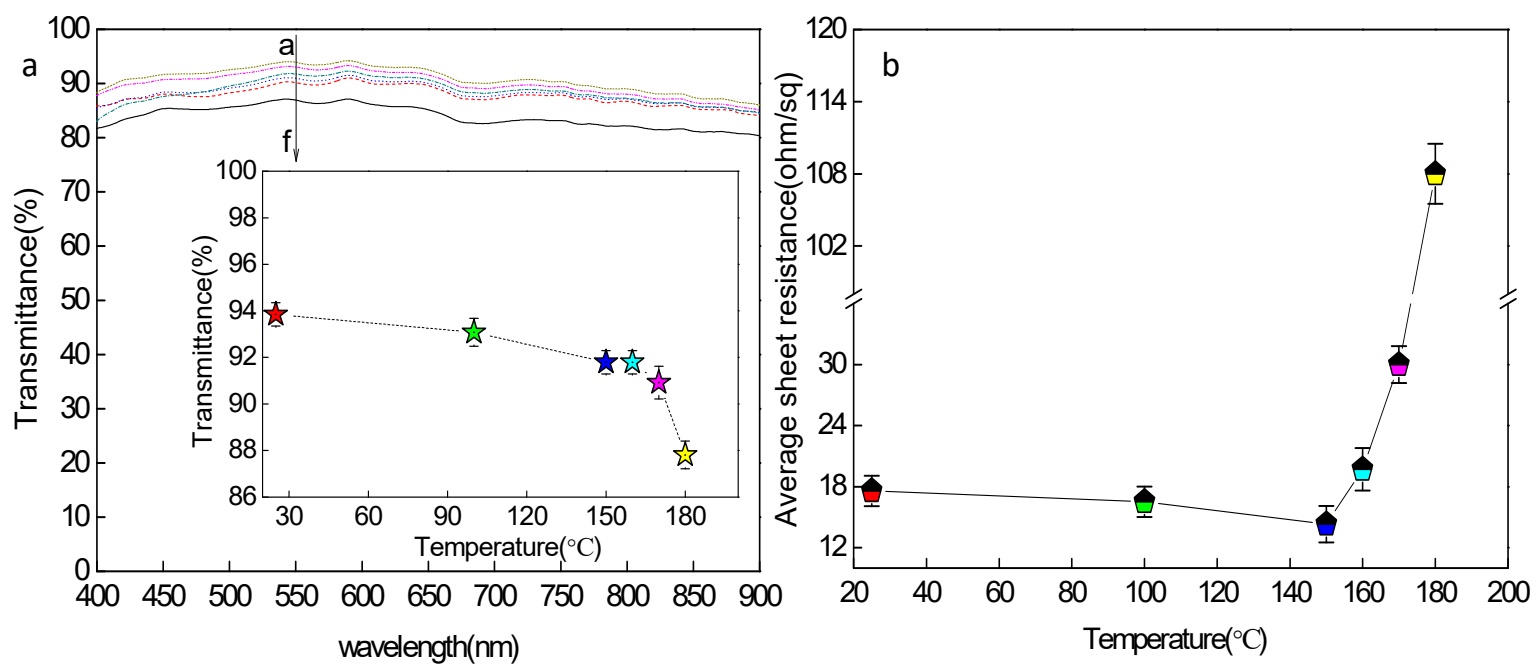

Figure 5. Transmittance (a); and sheet resistances (b) of films treated at different temperatures for $20 \mathrm{~min}$. Curves a-f in (a) represent samples heated at $25,100,150,160,170$, and $180^{\circ} \mathrm{C}$, respectively. The inset in (a) shows the relationship between film transmittance at $550 \mathrm{~nm}$ and the heat treatment temperature.

\subsection{Electrothermal Performances of the Silver Nanowires Films}

To demonstrate the applicability of the flexible transparent conductive AgNWs film in the field of $\mathrm{TFH}$, we fabricated AgNWs films with sheet resistances of 10,35 , and $130 \Omega \cdot \mathrm{sq}^{-1}$ on PET substrates. The electrothermal performances of the AgNWs film heater were studied by applying direct current to the AgNWs films in a laboratory environment, as schematically illustrated in Figure 1b. Figure 6 shows a plot of temperature versus time for the AgNWs conductive film with a sheet resistance of $10 \Omega \cdot \mathrm{sq}^{-1}$ under the operation for input voltage from 2 to $10 \mathrm{~V}$ (Figure 6a) and for different sheet resistances with an input voltage of $10 \mathrm{~V}$ (Figure 6b). As shown in Figure 6a, when the input voltages were 5, 7 , and $10 \mathrm{~V}$, the electrical powers were $2.5,4.9$, and $10 \mathrm{~W}$, respectively, and the film's temperatures reached 57,70 , and $110{ }^{\circ} \mathrm{C}$, respectively, confirming that the devices were able to operate with low input voltages. The experimental results indicate that the efficient transduction of electrical energy into Joule heating was caused by the good conductivity of the AgNWs film. Meanwhile, it is worth pointing out that, when the input voltage was in the range of $2-10 \mathrm{~V}$, the film took less than $40 \mathrm{~s}$ to reach its steady-state temperature, demonstrating fast response of the AgNWs film heater. The results therefore demonstrate that the film is very suitable for applications in the field of the fast temperature switching with low input voltages. As shown in Figure $6 \mathrm{~b}$, when the input voltage was fixed at $10 \mathrm{~V}$, the maximum steady-state temperature achieved increased when the sheet resistance of AgNW film was decreased. When the sheet resistance of the AgNWs film was 10, 35, or $130 \Omega \cdot \mathrm{sq}^{-1}$, the maximum steady-state temperature was 56,67 , or $110^{\circ} \mathrm{C}$, respectively; those values indicate that a sheet resistance of the film in the range of $10-35 \Omega \cdot \mathrm{sq}^{-1}$ is ideal for heating application and that the film exhibited good electrothermal conversion properties.

In addition, it should pointed out that we measured the transmittance and sheet resistance of corresponding samples (Figure 6a) after being treated at 3, 5, 7, and $10 \mathrm{~V}$. There were no significant changes in the sheet resistance and the transmittance. This result might be an indication that the temperature of the sample was not too high. 

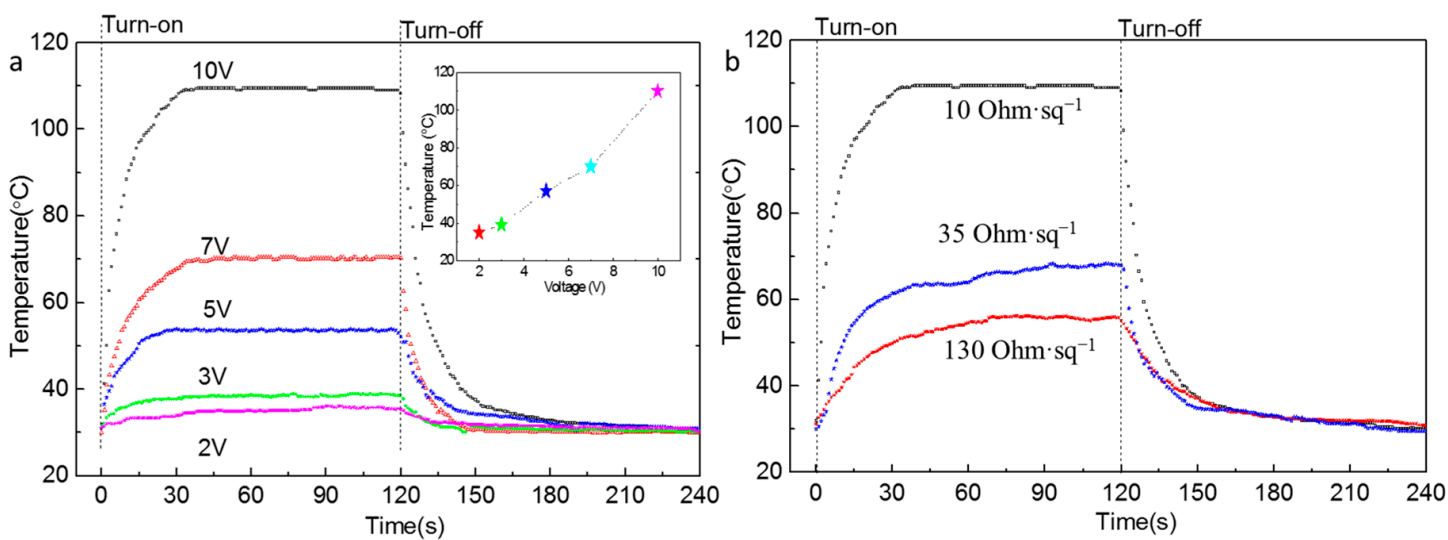

Figure 6. Temperature versus time for: the TFH with the sheet resistance of $10 \Omega \cdot \mathrm{sq}^{-1}$ under operation with different input voltages (a); and with different sheet resistances under operation with an input voltage of $10 \mathrm{~V}(\mathbf{b})$. The inset in (a) shows the relationship between the input voltage and the maximum steady-state temperature.

Figure 7 shows infrared images of AgNWs film heaters with $10 \Omega \cdot \mathrm{sq}^{-1}$ after being operated at different input voltages for $2 \mathrm{~min}$ (Figure 7a) and AgNW films with different sheet resistances under the operation at input voltage of $10 \mathrm{~V}$ (Figure 7b). The infrared image in Figure 7a shows low contrast owing to the low temperature generated by the low input voltage $(2 \mathrm{~V})$. However, as the input voltage was increased, the temperature of the AgNW film increased, and the infrared images clearly displayed a uniform heat distribution across the film. Conversely, non-uniform AgNWs networks often cause "hot spots", as can be seen in Figure $7 \mathrm{~b}\left(130 \Omega \cdot \mathrm{sq}^{-1}\right)$; these hot spots were mainly caused by aggregates of the AgNWs.
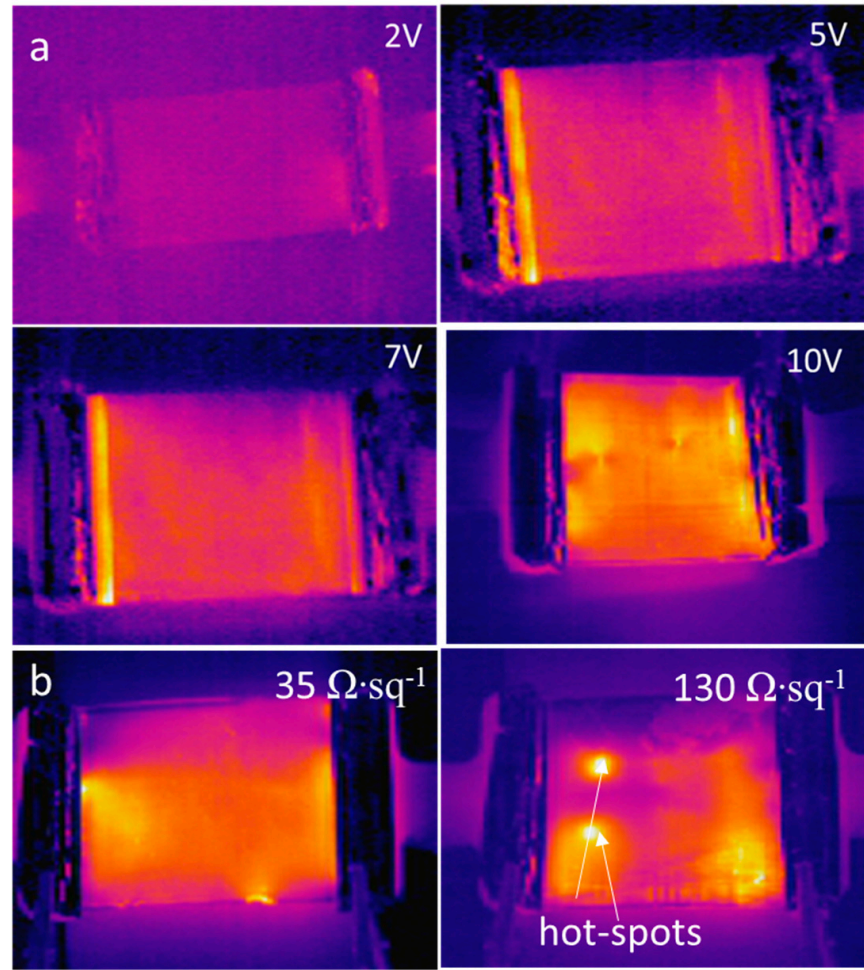

Figure 7. Infrared images of: AgNW film heaters with $10 \Omega \cdot \mathrm{sq}^{-1}$ after operation at different input voltages for $2 \mathrm{~min}(\mathbf{a})$; and AgNW films with different sheet resistances under operation at input voltage of $10 \mathrm{~V}(\mathbf{b})$. 
To demonstrate the applicability of the AgNW film and the large-area scalability of our process, we fabricated AgNWs film with size of $360 \times 270 \mathrm{~mm}^{2}$ on a PET substrate. The film was prepared using $3 \mathrm{~mL}$ of a AgNWs solution with a concentration of $2.0 \mathrm{~mol} \cdot \mathrm{L}^{-1}$ and the Meyer rod was moved at a speed of $0.03 \mathrm{~mm} / \mathrm{s}$. We measured the film's sheet resistance, transmittance, haze, and RMS roughness value. Figure 8 shows a photograph and a 3D AFM image of the sample. We placed a device operating with a blue light emitting diode (LED) on the AgNWs film to measure its transmittance and constructed an AgNWs film heater, as shown Figure $1 \mathrm{~b}$. The sheet resistance, transmittance, and haze were found to be $38.6 \Omega \cdot \mathrm{sq}^{-1}, 92.3 \%$, and $1.16 \%$, respectively, indicating that the sample has excellent optoelectronic properties when applied to PET substrate. The RMS roughness was 16.9, which demonstrates the good surface topography of the sample.
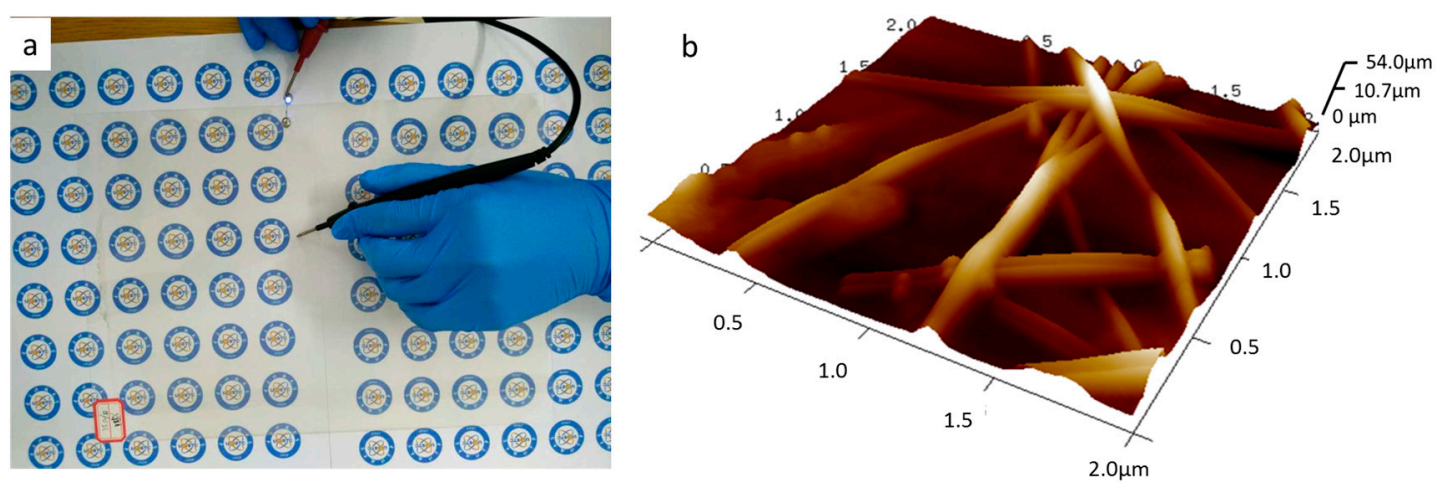

Figure 8. Photograph (a); and 3D AFM image (b) of the sample.

Figure 9 shows the photographs of the LED light on the AgNW film (Figure 9a) and infrared images of the AgNWs film heater (Figure $9 \mathrm{~b}$ ) as well as the relative change in sheet resistance of the film ( $R$ and $R_{0}$ represent the sheet resistance of films before and after bending test, respectively) versus the number of conducted bending cycles (Figure 9c). Figure 9 clearly shows that the LED's light was transmitted through the sample and that the bent conductive film still worked normally. Furthermore, the infrared images of the sample show a uniform heat distribution across the whole surface of the film during both outward and inward bending, indicating that the AgNWs films have a good mechanical flexibility. Figure $9 \mathrm{c}$ shows that the relative change in sheet resistance of the film over 300 bending cycles of outward and inward bending was less than 1.5, indicating that the mechanical stability of the AgNW film is insufficient owing to weak adhesion between the AgNWs and the substrate. However, the film still exhibited a good conductivity and heating performance, as shown in Figure 9a,b. 

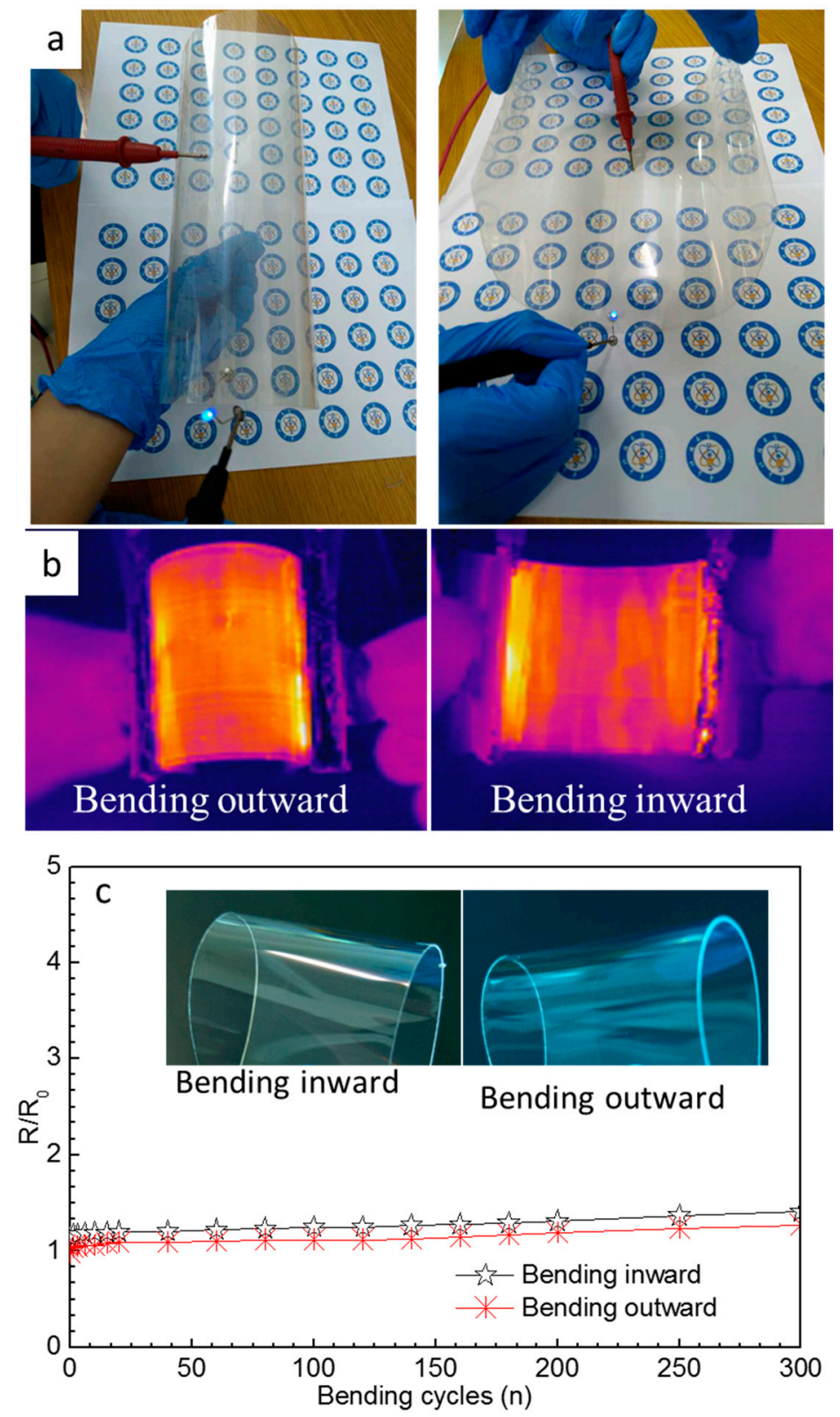

Figure 9. Photographs of an LED placed under the AgNW film during inward and outward bending (a); infrared images of the AgNW film heater bent inward and outward (b); and the relative change in the sheet resistance of the film versus the number of bending cycles (c).

\section{Conclusions}

We fabricated transparent films composed of AgNWs with diameters of 20-30 nm and lengths of 25-30 $\mu \mathrm{m}$ on PET substrates and glass slides via the Meyer rod method. We systematically investigated the AgNW films' optoelectronic and electrothermal properties. Our experimental results demonstrate that the morphology of the AgNWs showed no significant change when heat-treated at $25-150{ }^{\circ} \mathrm{C}$, and that the AgNW film had a high conductivity (17.6-14.3 $\left.\Omega \cdot \mathrm{sq}^{-1}\right)$, excellent transmittance (93.9-91.8\%), and low surface roughness $(11.2-14.7 \mathrm{~nm})$. We then increased the heat treatment temperature from 170 to $250{ }^{\circ} \mathrm{C}$, which caused the AgNWs to gradually sinter, thereby fusing them together (initially into discontinuous segments and finally into large droplets), which resulted in the conductivity of the film decreasing, until it became non-conductive. We fabricated a transparent AgNW film heater that displayed effective and rapid heating at low input voltages owing to the good conductivity of the AgNW film. With an input voltage in the range of 2-10 V, the film took less than $40 \mathrm{~s}$ to reach a 
steady-state temperature, demonstrating the fast response of the AgNW film heater. When the sheet resistance of the AgNWs film was 10, 35, and $130 \Omega \cdot \mathrm{sq}^{-1}$, the maximum steady-state temperature was 56,67 , and $110^{\circ} \mathrm{C}$, respectively, which indicates good electrothermal conversion behavior of the film for a sheet resistance in the range of $10-35 \Omega \cdot \mathrm{sq}^{-1}$. The conductivity of the film decreased for an increasing number of bending cycles; however, the film still exhibited a good conductivity and heating performances after repeated bending.

Supplementary Materials: The following are available online at http://www.mdpi.com/2079-4991/9/6/904/s1, Figure S1. Optical microscope photos of AgNW films treated at (a) 25, (b) 100, (c) 150, (d) 170, (e) 200, and (f) $250^{\circ} \mathrm{C}$ for 20 min. (1000× magnification); Figure S2. 3D AFM images of the AgNWs films treated at (a) 25, (b) 100, (c) 150, (d) 170 , (e) 200 , and (f) $250^{\circ} \mathrm{C}$ for $20 \mathrm{~min}$.

Author Contributions: Conceptualization, Y.W. and Y.Z.; methodology, Y.W. and X.Y.; software, X.Y.; validation, X.Y. and D.D.; formal analysis, X.Y.; investigation, X.Y. and D.D.; resources, Y.W. and Y.Z.; data curation, X.Y. and D.D.; writing-original draft preparation, Y.W. and X.Z.; writing-review and editing, Y.W.; visualization, Y.Z. and X.Z.; supervision, X.Y.; project administration, Y.W.; funding acquisition, Y.W.

Funding: This work was financially supported by National Science Foundation of China (grant numbers 61302044 and 61671140) and Zhongshan Science and Technology Projects (2018SYF10).

Conflicts of Interest: The authors declare no conflict of interest.

\section{References}

1. Leem, D.S.; Edwards, A.; Faist, M.; Nelson, J.; Bradley, D.D.C.; Mello, J.C. Efficient organic solar cells with solution-processed slver nanowire electrodes. Adv. Mater. 2011, 23, 4371-4375. [CrossRef] [PubMed]

2. Kumar, D.; Stoichkow, V.; Brousseau, E.; Smith, G.C.; Kettle, J. High performing AgNW transparent conducting electrodes with a sheet resistance of $2.5 \Omega \cdot \mathrm{sq}^{-1}$ post-processing technique. Nanoscale 2019, 11, 5760-5769. [CrossRef] [PubMed]

3. Secor, E.B.; Lim, S.; Zhang, H.; Frisbie, C.D.; Francis, L.F.; Hersam, M.C. Gravure printing of graphene for large-area flexible electronics. Adv. Mater. 2014, 26, 4533-4538. [CrossRef] [PubMed]

4. Tung, T.T.; Alotaibi, F.; Nine, M.J.; Silva, R.; Tran, D.N.H.; Janowska, I.; Losic, D. Engineering of highly conductive and ultra-thin nitrogen-doped graphene films by combined methods of microwave irradiation, ultrasonic spraying and thermal annealing. Chem. Eng. J. 2018, 338, 764-773. [CrossRef]

5. Wang, P.; Peng, Z.; Li, M. Stretchable Transparent conductive films from long carbon nanotube metals. Small 2018, 14, 1802625. [CrossRef] [PubMed]

6. Araki, T.; Jiu, J.; Nogi, M.; Koga, H.; Nagao, S.; Sugahara, T.; Suganuma, K. Low haze transparent electrodes and highly conducting air dried films with ultra-long silver nanowires synthesized by one-step polyol method. Nano Res. 2014, 7, 236-245. [CrossRef]

7. Li, D.; Han, T.; Ruan, H. Solution-Assembled Ordered Grids Constructed with Silver Nanowires as Transparent Conductive Electrodes. ACS Omega 2018, 3, 7191-7195. [CrossRef]

8. Yang, X.; Du, D.; Wang, Y.H. Length-dependent electro-optical properties of silver nanowires-based transparent conducting films. J. Mater. Sci. Mater. Electron. 2019, 30, 6838-6845. [CrossRef]

9. Schumann, M.F.; Fritz, B.; Eckstein, R.; Lemmer, U.; Gomard, G.; Wegener, M. Cloaking of metal grid electrodes on Lambertian emitters by free-form refractive surfaces. Opt. Lett. 2018, 43, 527-530. [CrossRef]

10. Abduev, A.; Akmedov, A.; Asvarov, A.; Chiolerio, A. A Revised Growth Model for Transparent Conducting Ga Doped ZnO Films: Improving Crystallinity by Means of Buffer Layers. Plasma Process. Polym. 2015, 12, 725-733. [CrossRef]

11. Chen, W.C.; Lien, H.T.; Cheng, T.W.; Su, C.; Chong, C.W.; Ganguly, A.; Chen, K.H.; Chen, L.C. Side group of poly(3-alkylthiophene)s controlled dispersion of single-walled carbon nanotubes for transparent conducting Film. ACS Appl. Mater. Interfaces 2015, 7, 4616-4622. [CrossRef] [PubMed]

12. Kim, S.; Kim, B.; Im, I.; Kim, D.; Lee, H.; Nam, J.; Chung, H.K.; Lee, H.J.; Cho, S.M. Employment of gold-coated silver nanowires as transparent conductive electrode for organic light emitting diodes. Nanotechnology 2017, 28, 345201. [CrossRef]

13. Sohn, H.; Woo, Y.S.; Shin, W.; Yun, D.J.; Lee, T.; Kim, F.S.; Hwang, J. Novel transparent conductor with enhanced conductivity: Hybrid of silver nanowires and dual-doped grapheme. Appl. Surf. Sci. 2017, 419, 63-66. [CrossRef] 
14. Chen, C.; Zhao, Y.; Wei, W.; Tao, J.; Lei, G.D.; Wan, M.; Li, S.; Ji, S.; Ye, C. Fabrication of silver nanowire transparent conductive films with an ultra-low haze and ultra-high uniformity and their application in transparent electronics. J. Mater. Chem. C 2017, 5, 2240-2246. [CrossRef]

15. Hemmati, S.; Barkey, D.P. Parametric Study, Sensitivity Analysis, and Optimization of Polyol Synthesis of Silver Nanowires. ECS J. Solid State Sci. Technol. 2017, 6, 132-137. [CrossRef]

16. Kwon, J.; Suh, Y.D.; Lee, J.; Lee, P.; Han, S.; Hong, S.; Yeo, J.; Lee, H.; Ko, S.H. Recent progress in silver nanowire based flexible/wearable optoelectronics. J. Mater. Chem. C 2018, 6, 7445-7461. [CrossRef]

17. Bergin, S.M.; Chen, Y.H.; Rathmell, A.R.; Charbonneau, P.; Li, Z.Y.; Wiley, B.J. The effect of nanowire length and diameter on the properties of transparent, conducting nanowire films. Nanoscale 2012, 4, 1996-2004. [CrossRef] [PubMed]

18. Jia, Y.G.; Chen, C.; Jia, D.; Li, S.X.; Ji, S.L.; Ye, C.H. Silver Nanowire Transparent Conductive Films with High Uniformity Fabricated via a Dynamic Heating Method. ACS Appl. Mater. Interfaces 2016, 8, 9865-9871. [CrossRef]

19. Liu, R.; Tan, M.; Zhang, X.; Xu, L.; Chen, J.; Chen, Y.; Tang, X.; Wan, L. Solution-processed composite electrodes composed of silver nanowires and aluminum-doped zinc oxide nanoparticles for thin-film solar cells applications. Sol. Energy Mater. Sol. Cells 2018, 174, 584-592. [CrossRef]

20. Jo, W.; Kang, H.S.; Choi, J.; Lee, H.; Kim, H.-T. Plasticized Polymer Interlayer for Low-Temperature Fabrication of a High-Quality Silver Nanowire-Based Flexible Transparent and Conductive Film. ACS Appl. Mater. Interfaces 2017, 9, 15114-15121. [CrossRef]

21. Lagrange, M.; Langley, D.P.; Giusti, G.; Jimenez, C.; Bréchet, Y.; Bellet, D. Optimization of silver nanowire-based transparent electrodes: Effects of density, size and thermal annealing. Nanoscale 2015, 7, 17410-17423. [CrossRef] [PubMed]

22. Wang, J.; Jiu, J.; Araki, T.; Nogi, M.; Sugahara, T.; Nagao, S.; Koga, H.; He, P.; Suganuma, K. Silver Nanowire Electrodes: Conductivity Improvement Without Post-treatment and Application in Capacitive Pressure Sensors. Nano-Micro Lett. 2015, 7, 51-58. [CrossRef] [PubMed]

23. Xu, W.; Xu, Q.S.; Huang, Q.J.; Tan, R.Q.; Shen, W.F.; Song, W.J. Fabrication of Flexible Transparent Conductive Films with Silver Nanowire by Vacuum Filtration and PET Mold Transfer. J. Mater. Sci. Technol. 2016, 32, 158-161. [CrossRef]

24. Tang, L.; Zhang, J.; Dong, L.; Pan, Y.; Yang, C.; Li, M.; Ruan, Y.; Ma, J.; Lu, H. Coating-free, air-stable silver nanowires for high-performance transparent conductive film. Nanotechnology 2018, 29, 375601. [CrossRef] [PubMed]

25. Zhang, Y.; Guo, J.N.; Xu, D.; Sun, Y.; Yan, F. One-pot synthesis and purification of ultra-long silver nanowires for flexible transparent conductive electrodes. ACS Appl. Mater. Interfaces 2017, 9, 25465-25473. [CrossRef]

26. Sorel, S.; Lyons, P.E.; De, S.; Dickerson, J.C.; Coleman, J.N. The dependence of the optoelectrical properties of silver nanowire networks on nanowire length and diameter. Nanotechnology 2012, 23, 185201. [CrossRef] [PubMed]

27. Liu, Y.; Chen, Y.Y.; Shi, R.; Cao, L.; Wang, Z.; Sun, T.; Lin, J.; Liu, J.; Huang, W. High-yield and rapid synthesis of ultrathin silver nanowires for low-haze transparent conductors. RSC Adv. 2017, 7, 4891-4895. [CrossRef]

28. Chang, J.H.; Chiang, K.M.; Kang, H.W.; Chi, W.J.; Chang, J.H.; Wu, C.I.; Lin, H.W. A solution-processed molybdenum oxide treated silver nanowire network: A highly conductive transparent conducting electrode with superior mechanical and hole injection properties. Nanoscale 2015, 7, 4572-4579. [CrossRef]

29. Chiang, K.M.; Huang, Z.Y.; Tsai, W.L.; Lin, H.W. Orthogonally weaved silver nanowire networks for very efficient organic optoelectronic devices. Org. Electron. 2017, 43, 15-20. [CrossRef]

30. Kang, S.; Kim, T.; Cho, S.; Lee, Y.; Choe, A.; Walker, B.; Ko, S.J.; Kim, J.Y.; Ko, H. Capillary Printing of Highly Aligned Silver Nanowire Transparent Electrodes for High-Performance Optoelectronic Devices. Nano Lett. 2015, 15, 7933-7942. [CrossRef]

31. Novara, C.; Petracca, F.; Virga, A.; Rivolo, P.; Ferrero, S.; Chiolerio, A.; Geobaldo, F.; Porro, S.; Fabrizio Giorgis, F. SERS active silver nanoparticles synthesized by inkjet printing on mesoporous silicon. Nanoscale Res. Lett. 2014, 9, 527. [CrossRef] [PubMed]

32. Castellino, M.; Chiolerio, A.; Shahzad, M.I.; Jagdale, P.V.; Tagliaferro, A. Electrical conductivity phenomena in an epoxy resin-carbon-based materials composite. Compos. Part A Appl. Sci. Manuf. 2014, 61, 108-114. [CrossRef] 
33. Marus, M.; Hubarevich, A.; Lim, R.J.W.; Huang, H.; Smirnov, A.; Wong, H.; Fan, W.J.; Sun, X.W. Effect of silver nanowire length in a broad range on optical and electrical properties as a transparent conductive film. Opt. Mater. Express 2017, 7, 1105-1112. [CrossRef]

34. Mayoral, A.; Allard, L.F.; Ferrer, D.; Esparza, R.; Yacaman, M.J. On the behavior of Ag nanowires under high temperature: In situ characterization by aberration-corrected STEM. J. Mater. Chem. 2011, 21, 893-898. [CrossRef]

35. Komoda, N.; Nogi, M.; Suganuma, K.; Kohno, K.; Akiyama, Y.; Otsuka, K. Printed silver nanowire antennas with low signal loss at high-frequency radio. Nanoscale 2012, 4, 3148-3153. [CrossRef] [PubMed]

36. Chiolerio, A.; Cotto, M.; Pandolfi, P.; Martino, P.; Camarchia, V.; Pirola, M.; Ghione, G. Ag nanoparticle-based inkjet printed planar transmission lines for RF and microwave applications: Considerations on ink composition, nanoparticle size distribution and sintering time. Microelectron. Eng. 2012, 97, 8-15. [CrossRef]

37. Kang, J.; Ryu, J.; Kim, H.; Hahn, H. Sintering of Inkjet-Printed Silver Nanoparticles at Room Temperature using Intense Pulsed Light. J. Electron. Mater. 2011, 40, 2268-2277. [CrossRef]

38. Hwang, H.-Y.; Malhotra, R. Shape-Tuned Junction Resistivity and Self-Damping Dynamics in Intense Pulsed Light Sintering of Silver Nanostructure Films. ACS Appl. Mater. Interfaces 2019, 11, 3536-3546. [CrossRef]

39. Wang, F.; Tang, Z.; He, H. Stress-Dislocation Interaction Mechanism in Low-Temperature Thermo-Compression Sintering of Ag NPs. AIP Adv. 2018, 8, 045012. [CrossRef]

40. Wakai, F.; Brakke, K.A. Mechanics of Sintering for Coupled Grain Boundary and Surface Diffusion. Acta Mater. 2011, 59, 5379-5387. [CrossRef]

(C) 2019 by the authors. Licensee MDPI, Basel, Switzerland. This article is an open access article distributed under the terms and conditions of the Creative Commons Attribution (CC BY) license (http://creativecommons.org/licenses/by/4.0/). 